\title{
The Method of Randomization for Cluster-Randomized Trials: Challenges of Including Patients with Multiple Chronic Conditions
}

\author{
Denise Esserman ${ }^{1}$, Heather G. Allore ${ }^{1,2}$ and Thomas G. Travison ${ }^{3,4}{ }^{*}$ \\ ${ }^{1}$ Department of Biostatistics, Yale School of Public Health, New Haven, Connecticut, USA \\ ${ }^{2}$ Department of Internal Medicine, Yale School of Medicine, New Haven, Connecticut, USA \\ ${ }^{3}$ Department of Medicine, Harvard Medical School, Cambridge, Massachusetts, USA \\ ${ }^{4}$ Hebrew SeniorLife Institute for Aging Research, Roslindale, Massachusetts, USA
}

\begin{abstract}
Cluster-randomized clinical trials (CRT) are trials in which the unit of randomization is not a participant but a group (e.g. healthcare systems or community centers). They are suitable when the intervention applies naturally to the cluster (e.g. healthcare policy); when lack of independence among participants may occur (e.g. nursing home hygiene); or when it is most ethical to apply an intervention to all within a group (e.g. school-level immunization). Because participants in the same cluster receive the same intervention, CRT may approximate clinical practice, and may produce generalizable findings. However, when not properly designed or interpreted, CRT may induce biased results.

CRT designs have features that add complexity to statistical estimation and inference. Chief among these is the clusterlevel correlation in response measurements induced by the randomization. A critical consideration is the experimental unit of inference; often it is desirable to consider intervention effects at the level of the individual rather than the cluster. Finally, given that the number of clusters available may be limited, simple forms of randomization may not achieve balance between intervention and control arms at either the cluster- or participant-level.

In non-clustered clinical trials, balance of key factors may be easier to achieve because the sample can be homogenous by exclusion of participants with multiple chronic conditions (MCC). CRTs, which are often pragmatic, may eschew such restrictions. Failure to account for imbalance may induce bias and reducing validity. This article focuses on the complexities of randomization in the design of CRTs, such as the inclusion of patients with MCC, and imbalances in covariate factors across clusters.
\end{abstract}

Keywords: Experimental Design, Randomization, Cluster Randomized Trials, Multiple Chronic Conditions.

\section{INTRODUCTION}

The US Department of Health and Human Services has made addressing clinical trials of people with multiple chronic conditions (MCC) a priority [1]. People with MCC take multiple medications, which are rarely tested together in a randomized clinical trial. In fact, these individuals are often excluded from trials as a matter of course in order to decrease potential sources of variation and bias.

Thus, trials in this area may not be generalizable to the most important clinical populations. This is a major concern; for results to be applicable to clinical practice, it is essential that an intervention is effective in the true target population, not only in idealized samples. Accordingly, recent guidance has emphasized [2] "the FDA's interest in encouraging a broad population sample in the development of new drugs."

A key first step in trial design is determining how best to randomize participants. The balance among

*Address correspondence to this author at the Hebrew SeniorLife Institute for Aging Research, Harvard University, 1200 Centre Street, Boston, MA 02131, USA; Tel: 617.923.7747; E-mail: tgt@hsl.harvard.edu arms of observed and unobserved factors is a goal of randomization for unbiased estimation of intervention effects. Cluster randomized trials (CRT) - in which the unit of randomization is a group of participants [3,4], or "cluster" - are relevant for interventions applied at the level of the group, and may offer some advantages in trials enrolling participants with MCC. There are substantial difficulties introduced by clustered sampling of participants, stemming largely from the correlation between individuals enrolled within a cluster [5]. Here we provide a brief overview of randomization in CRTs, discuss the pros and cons of these designs for complex patient populations, and propose a direction for future methodological development in this area.

\section{THE ROLE OF RANDOMIZATION}

We rely upon randomization to achieve comparable treatment and control arms, balanced on both measured and unmeasured factors, so that the difference between them can be given a causal interpretation [6,7]. While the benefits of simple randomization follow readily when the number of randomized units is large (e.g. the number of participants in a large, non-clustered trial), they may not hold when the number of randomized units is small. 
In a CRT, the unit of randomization is the cluster, and these may be few in number. In this situation, there is a much greater probability of not achieving balance between trial arms under simple randomization schemes, compromising the validity of the trial results. Therefore, refinements on more simple methods of randomization are often necessary. There has been substantial attention to the problem of obtaining balance on covariates at the time of randomization, but numerous difficulties persist [8].

\section{BALANCING CLUSTERS IN RANDOMIZED DESIGNS}

When deciding on the best way to randomize clusters to ensure balance across treatment arms, we must first decide whether the unit of inference will be the cluster or rather the participant [9]. In the former case, simple methods may be used to compare, for instance, the mean rate of change on some outcome in treatment clusters versus control clusters, and for each cluster the outcomes data are reduced to the average rate of change for that cluster. Covariates are likewise applicable to the cluster itself and are taken to apply to it as a whole. Under this paradigm, comparability of treatment and control units randomized is equivalent to comparability of cluster-level factors; these should in principle be balanced by even simple randomization of clusters, though in practice the number of clusters is often too few to insure this.

When the unit of inference is the individual, by contrast, it is necessary that one be able to estimate the difference between comparable individuals assigned to treatment and to control. Comparability at the level of the individual, however, is not directly addressed by simple randomization of clusters to treatment and control. Imbalance among important characteristics may cause confounding of treatment and prognostic factors and adversely affect the interpretation and finding of the trial [10]. This may be further complicated by design elements - for instance, in situations where one is interested in a subset of individuals within each cluster, due to trial exclusions or limits on enrollment. If not all patients from a cluster are enrolled and those patients enrolled do not reflect the aggregate characteristics of the cluster, there could be severe imbalances at the level of the individual. This is especially applicable for trials with patients with MCC, who may often be excluded from participation and/or be unevenly distributed among geographic regions, hence across randomized clusters. Typically, trial designers do not have the necessary composite cluster-level characteristics or individual-level characteristics available for study until after participant enrollment and cluster randomization has occurred. Therefore, trial designers must rely on data from secondary sources. If these data are available, methods may be deployed to assist in balancing on these factors, but rely on the applicability of these data to the current trial population.

\section{SIMULTANEOUS VS. RANDOMIZATION SCHEMES \\ SEQUENTIAL}

Randomization methods can broadly be divided into simultaneous and sequential schemes. A summary of some of the most common methods available is presented in Table 1; each has its own advantages and disadvantages. In simultaneous randomization, the full sampling frame is created and all clusters are randomized prior to enrollment of participants. This approach is easier to operationalize as the randomized units can begin preparations and participant enrollments at the same time. They have as a limitation, however, the fact that they cannot be modified after the fact. Several methods of restricted or constrained randomization, simultaneous approaches, have been proposed to achieve overall balance in trials, especially when a small number of units (i.e. participants or clusters) are being randomized. For example, in one trial of ten universities in North Carolina a matching process was used before randomization to achieve balance between the schools in the two arms [11].

In sequential randomization, clusters are randomized over time as they are included in the study. This approach, though more difficult to implement, in principle allows for consideration of balance as an evolving state that can be monitored and controlled via randomization as the trial proceeds. Adaptive randomization - in which features of the design are changed or updated in response to the current state of enrollment - can be considered an important subset of sequential schemes, but few adaptive cluster randomization methods have been described in the literature.

As difficulty in enrolling enough participants is a key hurdle in randomized trials, an important challenge in maintaining the balance between arms after the initial randomization occurs when clusters need to be added, typically to meet recruitment goals. Randomization methods that allocate units in a sequential manner (e.g. baseline covariate adaptive randomization [10,12]) 
allow for the addition of participants later in the trial, but require flexibility on the part of investigators and trial centers. If investigators cannot stagger enrollment across centers or they do not have a large enough pool of clusters, these methods still may not be practical. In simultaneous schemes (e.g. covariate constrained randomization) $[13,14]$, there is no defined method to include additional clusters once the initial randomization is completed. As noted above, these methods must rely on what limited data is available on key risk factors and/or only cluster level information is available at the time of study start. Given the desire to include participants with MCC and to conduct more pragmatic trials with diverse populations, there is a need to expand upon these methods to insure valid results.

\section{MULTIFACTORIAL INTERVENTIONS}

CRTs can be advantageous for testing multiplecomponent interventions tailored to an individual's risk factors, designs that we refer to as standardly-tailored. For example, an intervention may combine protein and vitamin D supplementation, where only participants below a certain daily intake of protein are considered for randomization to the former, and only those whose circulating vitamin $\mathrm{D}$ levels are below a certain threshold are considered for randomization to the latter. The standardly-tailored intervention allows participants to be enrolled in the trial as long as they have at least one of the risk factors. Participants randomized to intervention receive those components relevant to their status (in the example above, either protein or vitamin D supplementation or both), while those not randomized to intervention receive a placebo, standard care, or some other control regime. These designs are thus highly applicable to trials enrolling individuals with MCC.

A CRT of a standardly-tailored multi-component intervention produces a distribution of interventions and components with marked similarities to clinical practice in that, within clusters randomized to interventions, participants receive those components appropriate to their health state. Thus, standardly-tailored designs are highly pragmatic and may produce more immediately applicable findings. They also present sizable methodological challenges. In addition to the issues related to randomization described above, analyses of these designs must acknowledge that individuals may not be eligible or need every component of the intervention given their risk factor profile. In CRTs, this treatment (and corresponding risk factor) heterogeneity may exacerbate the complex imbalances that can occurs between clusters, as well as inducing different treatment effects among subpopulations of participants, which may in turn be unevenly spread across clusters.

\section{LIMITATIONS OF CLUSTER RANDOMIZED TRIAL DESIGNS}

While CRTs are advantageous and may closely represent clinical practice, they also present substantial challenges. With the movement toward inclusion of more complex patient populations and to more pragmatic clinical trials, the limits of the currently methodology will be tested, and refinements will prove necessary. However, the shift from CRT to pragmatic trials that may use cluster randomization often include a generalizable population and potentially many clusters, with few if any techniques available for balancing covariates. Trial designers should weight the tradeoffs of enrolling few large clusters (often fewer than 100), or many smaller clusters, which may be protected by randomization.

To date there is no established method describing the addition or replacement of a cluster following the use of matching or any of the simultaneous randomization schemes, such as covariate constrained randomization. The flexibility needed for large scale CRTs to meet the realities of the healthcare systems, clinical practices, and patient populations in which they are used makes some randomization procedures infeasible, while casting doubt on the applicability of others. As the call for pragmatic trials strengthens, there may be more emphasis to use trials that are broadly inclusive of people with MCC and other complex populations.

\section{CHALLENGES TO DEVELOPING CRT AMONG POPULATIONS WITH MCC}

The overarching methodologic challenges inherent in CRT designs [9,15-17] may be exacerbated by the demands of the specific patient population under study and inattention to best practices. Numerous authors have described the difficulties in developing and reporting CRT in primary care [18-20], cardiovascular health [21], nutrition [22], pediatrics [23], pain management [24], and other fields [25,26]. Even identifying published reports of CRT in a specific area can be difficult [27], and the quality of reporting of critical information may be lacking. A recent review estimated that fewer than one quarter of publications describing CRT provide tabular depictions of covariate data; only $17 \%$ of trials reporting the use of covariates 
Table 1: Description of Competing Randomization Procedures for Cluster Designs

\begin{tabular}{|c|c|c|c|}
\hline $\begin{array}{l}\text { Randomization } \\
\text { Procedure }\end{array}$ & Description & Advantages & Disadvantages \\
\hline $\begin{array}{c}\text { Simple } \\
\text { Randomization }\end{array}$ & $\begin{array}{c}\text { Unrestricted technique, based on single } \\
\text { sequence random assignment. All } \\
\text { allocations of units randomized are possible. }\end{array}$ & $\begin{array}{l}\text { Simple and easy to implement. } \\
\text { Balances covariates with large } \\
\text { sample sizes. }\end{array}$ & $\begin{array}{l}\text { Subjects enrolled may not have } \\
\text { balance on covariates when the } \\
\text { sample size is moderate or small. }\end{array}$ \\
\hline $\begin{array}{c}\text { Stratified } \\
\text { Randomization }\end{array}$ & $\begin{array}{c}\text { Restricted technique: Create a stratum for } \\
\text { each combination of covariates being } \\
\text { considered. Units are then randomly } \\
\text { assigned to treatment arms within each } \\
\text { stratum. }\end{array}$ & $\begin{array}{l}\text { Reduces imbalance between } \\
\text { treatment groups on important } \\
\text { covariates. Able to control and } \\
\text { balance covariates of } \\
\text { importance. }\end{array}$ & $\begin{array}{l}\text { Limited number of factors can be } \\
\text { stratified on, and need to be willing to } \\
\text { categorize continuous variables. } \\
\text { Number of strata needed increases } \\
\text { rapidly as the number of covariates } \\
\text { increases. }\end{array}$ \\
\hline Matching & $\begin{array}{l}\text { Restricted technique: Select from a smaller } \\
\text { set of all possible allocations, those fulfilling } \\
\text { certain restrictions (i.e. meet the matching } \\
\text { criteria), and then randomly allocate to the } \\
\text { treatment arms within each match. }\end{array}$ & $\begin{array}{l}\text { Reduces imbalance between } \\
\text { treatment groups on important } \\
\text { covariates. Able to control and } \\
\text { balance covariates of } \\
\text { importance. }\end{array}$ & $\begin{array}{l}\text { Need to identify pairs of clusters that } \\
\text { are well-matched on all of the risk } \\
\text { factors, which is often not feasible, } \\
\text { especially when subsets of people are } \\
\text { enrolled in each cluster post- } \\
\text { randomization. Need to set suitable } \\
\text { balance criteria. }\end{array}$ \\
\hline $\begin{array}{c}\text { Minimal } \\
\text { Sufficient } \\
\text { Balance [29] }\end{array}$ & $\begin{array}{l}\text { Restricted technique: Distribution of } \\
\text { covariates between treatment arms } \\
\text { assessed using imbalance tests, and } \\
\text { depending on results units are assigned } \\
\text { treatment based on biased coin or simple } \\
\text { random assignment }\end{array}$ & $\begin{array}{l}\text { Prevents serious imbalance on } \\
\text { important covariates, while } \\
\text { maintaining randomness of } \\
\text { treatment allocation. Do not } \\
\text { need to categorize covariates. }\end{array}$ & $\begin{array}{l}\text { Expected that units are being } \\
\text { randomized sequentially. Could be } \\
\text { deterministic. Need to set suitable } \\
\text { balance criteria. }\end{array}$ \\
\hline Minimization [10] & $\begin{array}{l}\text { Restricted technique: Sequentially assign } \\
\text { units to treatment groups taking into account } \\
\text { the balance on covariates and previous } \\
\text { randomization assignments. }\end{array}$ & $\begin{array}{l}\text { Maintains balance among } \\
\text { several covariates, while } \\
\text { minimizing imbalance in the } \\
\text { distribution of the treatment } \\
\text { across whole trial and each } \\
\text { stratification variable. }\end{array}$ & $\begin{array}{l}\text { Expectation is that units being } \\
\text { randomized are available sequentially, } \\
\text { which is usually not the case in a } \\
\text { cluster-randomized trial. Could have } \\
\text { imbalance in specific strata. Criticized } \\
\text { for being too deterministic. }\end{array}$ \\
\hline $\begin{array}{c}\text { Outcome } \\
\text { Adaptive } \\
\text { Randomization } \\
{[30]}\end{array}$ & $\begin{array}{l}\text { Restricted technique: Class of methods } \\
\text { including those proposed by Bather, [31] } \\
\text { Thompson, [32] Zelen, [33] Sobel and } \\
\text { Weiss, [34] and Berry and Fristedt, [35] in } \\
\text { which treatment assignment is dependent on } \\
\text { response of previous individuals. }\end{array}$ & $\begin{array}{l}\text { Objective is to maximize the } \\
\text { number of overall successes, } \\
\text { maximize effective treatment. }\end{array}$ & $\begin{array}{l}\text { Expected that units are being } \\
\text { randomized sequentially. Need real } \\
\text { time reporting of outcomes that can } \\
\text { be measured shortly after treatment } \\
\text { initiation, (e.g. pain relief for a } \\
\text { treatment). }\end{array}$ \\
\hline
\end{tabular}

in randomization adjusted for all of those covariates in analysis [28]. For populations with MCC, the reporting of illnesses, multimorbidity and other potential confounders is an obvious concern. Though few adaptive CRT have been published, a recent report describes difficulties common to all trials but of particular relevance to cluster designs, including a need to make unplanned revisions to the randomization scheme due to practical limitations on enrollment and retention [24]; it seems likely that cluster trials among participants with MCC would face similar challenges. More rigorous methods and enhanced guidance addressing these difficulties are needed.

\section{CONCLUSION}

CRTs offer considerable benefits in that they allow for the testing of complex interventions intended to 
produce change at the group level, and the manner in which they deploy interventions is somewhat more reminiscent of clinical practice than is the case in conventional randomized trials. However, there are substantial methodological costs accrued in deploying cluster designs. The issue of imbalance on confounders is a critical concern that is not addressed in simple randomization schemes. Methods for insuring balance can be deployed under simultaneous or sequential matching schemes, but these rely heavily on existing or accumulated data applicable to the trial population. If the unit of analysis is the participant, these difficulties can be substantially exacerbated. The benefits and weaknesses of the various approaches described in Table $\mathbf{1}$ should be carefully taken into account during the design of a CRT. Additionally, with increasing emphasis on pragmatic trials, as well as the inclusion of individuals with complex disease states, future expansion and refinement of these methods is of urgent importance.

\section{REFERENCES}

[1] Research C for DE and. Conducting Clinical Trials - U.S. Department of Health and Human Services' Initiative on Multiple Chronic Conditions. http://www.fda.gov/Drugs/ DevelopmentApprovalProcess/ConductingClinicalTrials/ucm3 79576.htm. Accessed November 25, 2015.

[2] FDA: Policies and Procedures for Proposed Trial Design Aimed at Multiple Chronic Conditions - Policy and Medicine. http://www.policymed.com/2014/02/fda-policies-andprocedures-for-proposed-trial-design-aimed-at-multiplechronic-conditions.html. Accessed November 25, 2015.

[3] Cornfield J. Randomization by group: a formal analysis. Am J Epidemiol 1978; 108(2): 100-102.

[4] Donner A, Klar N. Design and Analysis of Cluster Randomization Trials in Health Research. 1 edition. Chichester England: Wiley 2010.

[5] Campbell MK, Elbourne DR, Altman DG, CONSORT group. CONSORT statement: extension to cluster randomised trials. BMJ 2004; 328(7441): 702-708. http://dx.doi.org/10.1136/bmj.328.7441.702

[6] Suresh K. An overview of randomization techniques: An unbiased assessment of outcome in clinical research. J Hum Reprod Sci 2011; 4(1): 8-11.

http://dx.doi.org/10.4103/0974-1208.82352

[7] Hayes RJ, Moulton LH. Cluster Randomised Trials. 1 edition. Boca Raton: Chapman and Hall/CRC 2009.

http://dx.doi.org/10.1201/9781584888178

[8] Ivers NM, Halperin IJ, Barnsley J, et al. Allocation techniques for balance at baseline in cluster randomized trials: a methodological review. Trials 2012; 13: 120. http://dx.doi.org/10.1186/1745-6215-13-120

[9] Donner A, Klar N. Pitfalls of and controversies in cluster randomization trials. Am J Public Health 2004; 94(3): 416422 http://dx.doi.org/10.2105/AJPH.94.3.416

[10] Pocock SJ, Simon R. Sequential treatment assignment with balancing for prognostic factors in the controlled clinical trial. Biometrics 1975; 31(1): 103-115.

http://dx.doi.org/10.2307/2529712
Wolfson M, Champion $\mathrm{H}$, McCoy TP, et al. Impact of a randomized campus/community trial to prevent high-risk drinking among college students. Alcohol Clin Exp Res 2012; 36(10): 1767-1778.

http://dx.doi.org/10.1111/j.1530-0277.2012.01786.x

[12] Signorini DF, Leung O, Simes RJ, Beller E, Gebski VJ, Callaghan T. Dynamic balanced randomization for clinical trials. Stat Med 1993; 12(24): 2343-2350. http://dx.doi.org/10.1002/sim.4780122410

[13] Moulton LH. Covariate-based constrained randomization of group-randomized trials. Clin Trials 2004; 1(3): 297-305. http://dx.doi.org/10.1191/1740774504cn024oa

[14] Chaudhary MA, Moulton LH. A SAS macro for constrained randomization of group-randomized designs. Comput Methods Programs Biomed 2006; 83(3): 205-210. http://dx.doi.org/10.1016/i.cmpb.2006.04.011

[15] Hahn S, Puffer S, Torgerson DJ, Watson J. Methodological bias in cluster randomised trials. BMC Medical Research Methodology 2005; 5(1): 10

http://dx.doi.org/10.1186/1471-2288-5-10

[16] Weijer C, Grimshaw JM, Taljaard M, et al. Ethical issues posed by cluster randomized trials in health research. Trials $2011 ; 12(1): 100$

http://dx.doi.org/10.1186/1745-6215-12-100

[17] Christie J, O'Halloran P, Stevenson M. Planning a cluster randomized controlled trial: methodological issues. Nurs Res 2009; 58(2): 128-134. http://dx.doi.org/10.1097/NNR.0b013e3181900cb5

[18] Farrin A, Russell I, Torgerson D, Underwood M, UK BEAM Trial Team. Differential recruitment in a cluster randomized trial in primary care: the experience of the UK back pain exercise, active management and manipulation (UK BEAM) feasibility study. Clin Trials 2005; 2(2): 119-124. http://dx.doi.org/10.1191/1740774505cn073oa

[19] Eldridge SM, Ashby D, Feder GS, Rudnicka AR, Ukoumunne OC. Lessons for cluster randomized trials in the twenty-first century: a systematic review of trials in primary care. Clin Trials 2004; 1(1): 80-90.

http://dx.doi.org/10.1191/1740774504cn006rr

[20] Foster JM, Sawyer SM, Smith L, Reddel HK, Usherwood T. Barriers and facilitators to patient recruitment to a cluster randomized controlled trial in primary care: lessons for future trials. BMC Med Res Methodol 2015; 15. http://dx.doi.org/10.1186/s12874-015-0012-3

[21] Liddy C, Hogg W, Singh J, et al. A real-world stepped wedge cluster randomized trial of practice facilitation to improve cardiovascular care. Implement Sci 2015; 10 http://dx.doi.org/10.1186/s13012-015-0341-y

[22] Brown AW, Li P, Bohan Brown MM, et al. Best (but oftforgotten) practices: designing, analyzing, and reporting cluster randomized controlled trials. Am J Clin Nutr 2015; 102(2): 241-248.

http://dx.doi.org/10.3945/ajcn.114.105072

[23] Walleser S, Hill SR, Bero LA. Characteristics and quality of reporting of cluster randomized trials in children: reporting needs improvement. J Clin Epidemiol 2011; 64(12): 13311340.

http://dx.doi.org/10.1016/j.jclinepi.2011.04.006

[24] Ersek M, Polissar N, Du Pen A, Jablonski A, Herr K Neradilek MB. Addressing methodological challenges in implementing the nursing home pain management algorithm randomized controlled trial. Clin Trials 2012; 9(5): 634-644. http://dx.doi.org/10.1177/1740774512454243

[25] Froud R, Eldridge S, Diaz Ordaz K, Marinho VCC, Donner A Quality of cluster randomized controlled trials in oral health: a systematic review of reports published between 2005 and 2009. Community Dentistry and Oral Epidemiology 2012; 40: 3-14.

http://dx.doi.org/10.1111/j.1600-0528.2011.00660.x 
[26] Mbonye AK, Magnussen $\mathrm{P}$, Lal $\mathrm{S}$, et al. A Cluster Randomised Trial Introducing Rapid Diagnostic Tests into Registered Drug Shops in Uganda: Impact on Appropriate Treatment of Malaria. PLoS One 2015; 10(7).

http://dx.doi.org/10.1371/journal.pone.0129545

[27] Taljaard M, McGowan J, Grimshaw JM, et al. Electronic search strategies to identify reports of cluster randomized trials in MEDLINE: low precision will improve with adherence to reporting standards. BMC Med Res Methodol 2010; 10: 15.

http://dx.doi.org/10.1186/1471-2288-10-15

[28] Wright $\mathrm{N}$, Ivers $\mathrm{N}$, Eldridge S, Taljaard M, Bremner S. A review of the use of covariates in cluster randomized trials uncovers marked discrepancies between guidance and practice. J Clin Epidemiol 2015; 68(6): 603-609. http://dx.doi.org/10.1016/j.jclinepi.2014.12.006

[29] Zhao W, Hill MD, Palesch Y. Minimal sufficient balance--a new strategy to balance baseline covariates and preserve randomness of treatment allocation. Stat Methods Med Res 2015; 24(6): 989-1002.

http://dx.doi.org/10.1177/0962280212436447
[30] Zhang L, Rosenberger WF. Response-Adaptive Randomization for Clinical Trials with Continuous Outcomes. Biometrics 2006; 62(2): 562-569. http://dx.doi.org/10.1111/j.1541-0420.2005.00496.x

[31] Bather JA. Randomized Allocation of Treatments in Sequential Experiments. Journal of the Royal Statistical Society Series B (Methodological) 1981; 43(3): 265-292.

[32] Thompson WR. On the Likelihood That One Unknown Probability Exceeds Another in View of the Evidence of Two Samples. Biometrika 1933; 25(3-4): 285-294. http://dx.doi.org/10.1093/biomet/25.3-4.285

[33] Zelen M. Play the Winner Rule and the Controlled Clinical Trial. Journal of the American Statistical Association 1969; 64(325): 131-146. http://dx.doi.org/10.2307/2283724

[34] Sobel, Weiss: Play-the-Winner Rule and Inverse Sampling for Selecting the Best of $k>3$ Binomial Populations. Ann Math Stat 1972; 43(6): 1808-1826.

[35] Berry DA, Fristedt B. Bandit problems: Sequential Allocation of Experiments (Monographs on Statistics and Applied Probability). Springer 1985.

Received on 12-12-2015

Accepted on 23-12-2015

Published on 08-01-2016

http://dx.doi.org/10.6000/1929-6029.2016.05.01.1

(C) 2016 Esserman et al.; Licensee Lifescience Global.

This is an open access article licensed under the terms of the Creative Commons Attribution Non-Commercial License (http://creativecommons.org/licenses/by-nc/3.0/) which permits unrestricted, non-commercial use, distribution and reproduction in any medium, provided the work is properly cited. 